\title{
COORDINATION PROCESS AND NETWORK CENTRALITY IN ISGI AIRPORT'S WAYFINDING PROJECT
}

\author{
Sevgi Zeynep DOĞAN ${ }^{1}$, Ph.D., Suat GUNHAN², Ph.D., M.ASCE, Bengi \\ ERBASARANOĞLU ${ }^{3}$
}

${ }^{1}$ Izmir Institute of Technology, Dept. of Architecture, Izmir, Turkey, 35290; PH +90 (232) 750 7040; FAX +90 (232) 750 7012; e-mail: sevgidogan@iyte.edu.tr

${ }^{2}$ University of Texas at San Antonio, Construction Science \& Management Program, San Antonio, TX, 78207; PH +1(210)458-3181; FAX +1 (210) 458-3091; e-mail: suat.gunhan@utsa.edu

${ }^{3}$ Artek Project Consultancy Ltd., Çankaya, Ankara, Turkey, 06450; PH +90 (312) 472-7383; FAX +90 (312) 472-7384; e-mail: bengi@artekproje.com

\begin{abstract}
Coordination is integral to operational efficiency of construction projects. Coordination process relies on managing dependent activities and the structural centrality in social networks is strategic to project actor's management activity. This study aims to explore the effects of network centrality on coordination performance. Network centrality concepts and coordination theory are examined via e-mail communication data of İstanbul Sabiha Gökçen International Airport's (ISGIA) New Terminal Building Wayfinding and Signage Design Project (WSDP) actors. E-mail data mining for identifying different coordination dependencies is derived from the constructs of Malone's (1988) coordination theory and used to measure the actors' coordination scores. Social network matrix of information exchange network is constructed to calculate degree, betweenness and closeness centrality measures. ISGIA data analysis suggests a significant relationship between out-degree, outcloseness centrality and coordination. Findings highlight that out- network centralities support the ability of an actor to coordinate the dependent actions of other project actors; and the design and construction practices rely on the central position in a network in mapping effective coordination processes.
\end{abstract}

\section{INTRODUCTION}

Building design and construction represent a collective effort from project participants. A construction project involves diverse participants essentially collaborating closely. They are usually geographically separated when making interdependent decisions. This requires coordination to maintain compatibility. Coordination refers to specific protocols and procedures in conjunction with smooth flow of communication in all directions to achieve project objectives (Chitkara, 1998). Technical interdependency and organizational independency of construction projects demand improvement of coordination process to facilitate the efficient information flow and thus product quality (Saram and Ahmed, 2001; Mokhtar et al., 1998). Research that was made on critical success factors identified the efficiency of information exchange as a key factor in delivering high-performance projects (Chan, et. al., 2004). Project performance depends mainly on the effectiveness of coordination process results in communication networks rather than traditional benchmarks for the common factors of time, cost, and quality (Chinowsky, et al., 
2008). Obviously, the emphasis in such a discussion will be on the structural properties of human communication networks. The idea of centrality as applied to human communication was introduced by Bavelas (Freeman, 1979). He hypothesized a relationship between structural centrality and influence in group processes; then directed the first research application of centrality at the Massachusetts Institute of Technology (MIT). The experiment demonstrated a link between network centrality and coordination in small groups. In the late 1970s; Freeman et al. (1979/80) replicated the MIT experiment. Centrality has been defined by leading social network researchers as a measure of potential importance, influence, and prominence of an actor in a network (Freeman, 1979). Advances in technology have transformed instruments of information share and recently electronic mailing governed communication flow of construction projects' processes. The study analyzes coordination processes and network centrality in ISGIA New Terminal Building WSDP via project actors' e-mail communication data. The study investigates the differences in coordinative activity between the actors in respect to their positions in the organization network based on Malone's (1988) coordination theory along with the social network analysis (SNA) and its centrality measures.

\section{COORDINATION AND NETWORK STUDIES IN CONSTRUCTION}

Several coordination studies have been conducted in the design and construction domain. Saram and Ahmed (2001) investigated on the effectiveness of coordination in construction. The findings indicated that identifying strategic activities, potential delays and ensuring the timeliness of all work are the most important; conducting regular meetings, project reviews and analyzing the project performance are the most time-consuming construction coordination activities. Cheng et al.'s (2003) study pioneers quantitative evaluation to determine the optimal organizational structure which could promote coordination efficiency among team members. Mokhtar et al. (1998) presented an information model that facilitates the coordination of design information during the design change management process. Hossain (2009) investigated on how organizational network centrality affects the coordination effectiveness in a construction project. He studied SNA application to centrality measures in exploring correlation to coordination. SNA approach appeals to researchers in the construction domain due to its investigative capability of the various relationships among actors and organizations. In fact, several network studies have also been conducted in the construction domain. Studies primarily focused on SNA for issues of information exchange (Loosemore,1998) recognizing knowledge sharing to achieve high-performance teams (Chinowsky et al. 2008), and investigating high-performance teams both from the perspective of traditional project management and social networks (Chinowsky et al. 2010). Pryke conducted a series of SNA research focusing on project coalition, project governance and project procurement (Pryke, 2004; 2005; 2006). Recently, hybrid approaches suggested connecting social network theory with building information modeling (BIM) practice (Taylor and Bernstein, 2009). Centrality and coordination correlation widely discussed in social, math and physics studies (Freeman, et al., 1979/80; Latora and Marchiori, 2007); however the construction domain lacks such discussion apart from primary works of Hossain et al., (2006), and Hossain (2009). This study further tests the centrality and coordination association in design and construction projects. 


\section{PROJECT DESCRIPTION}

ISGIA is one of the two major airports, which is located on the Asian part of İstanbul. The ISGIA's new terminal building project aimed to serve 10 million passengers annually. The ISGIA was built by using build-operate-transfer (BOT) method which enables public private partnership (PPP). It is a very common approach used in airport projects in Turkey. The Owner of the project is the Turkish Republic Ministry of Defense Undersecretaries for Defense Industries which is represented by the Airport Management and Aviation Industry. The architectural design project was obtained via competition among four invited architectural design firms. The project was awarded to Tekeli-Sisa Architectural Partnership. The construction and operations of the ISGIA was transferred to the private enterprise (LIMAK-GMRMAHB Joint Venture) at the end of a bidding process for the amount of $€ 1$ billion 932 million (VAT excluded). LIMAK-GMR-MAHB established a construction contract with LIMAK-GMR to build the new terminal building. The contract amount was $€ 330,857,195$. LIMAK-GMR contracted with Tekeli-Sisa Architectural Partnership, and many other design firms to procure design and design specialty services. The major design specialty services included structural, mechanical, electrical, infrastructure, fuel hydrant, interiors, wayfinding, and landscape design. ISGIA information is gathered from Can (2010).

The WSDP of this new terminal building is used as a case study in this paper. The wayfinding project included all wayfinding design works and signage provisions for the new terminal building's interiors and exteriors (land and air). LIMAK-GMR subcontracted the wayfinding design and signage provisions to YÖNSİS. Schematic design for wayfinding and signage was provided by WOODHEAD, which worked as a subcontractor to YÖNSIS. YÖNSİS developed each sign type and specified materials and fabrication details, and also the font styles and colors. RGB Consulting had a contractual relationship with YÖNSIS and provided consulting services to improve the coordination process among all participants of the wayfinding and signage project. YÖNSİS also had a non-contractual, informational relationship with Tekeli-Sisa Architectural Partnership. In addition to these participants, Y1ldiz Technical University provided supervisory consulting services to Tekeli-Sisa Architectural Partnership on WSDP. Figure 1 shows ISGIA WSDP organizational schema.

\section{METHODOLOGY}

The study was performed by using the WSDP of ISGIA's e-mail communication dataset. The aim for particularly studying the e-mail communication dataset was the geographic separation of the project actors. The construction site was located in İstanbul. The general contractor, the architect and consulting firms were local project participants. The WSDP contractor was located in Izmir, Turkey and the sub-contractor was located in Adelaide, Australia. E-mail traffic lasted for six months. Entire email communication data of 256 sent and 219 received e-mails were reviewed by Erbasaranoglu (2011) who in the meantime was a project tem member of the WSDP contractor firm and had access to scan interfirm email exchange. E-mail communication data would more likely to show coordination as all the project actors could physically get together for only twice in İstanbul and communication via phone was rarely used. 


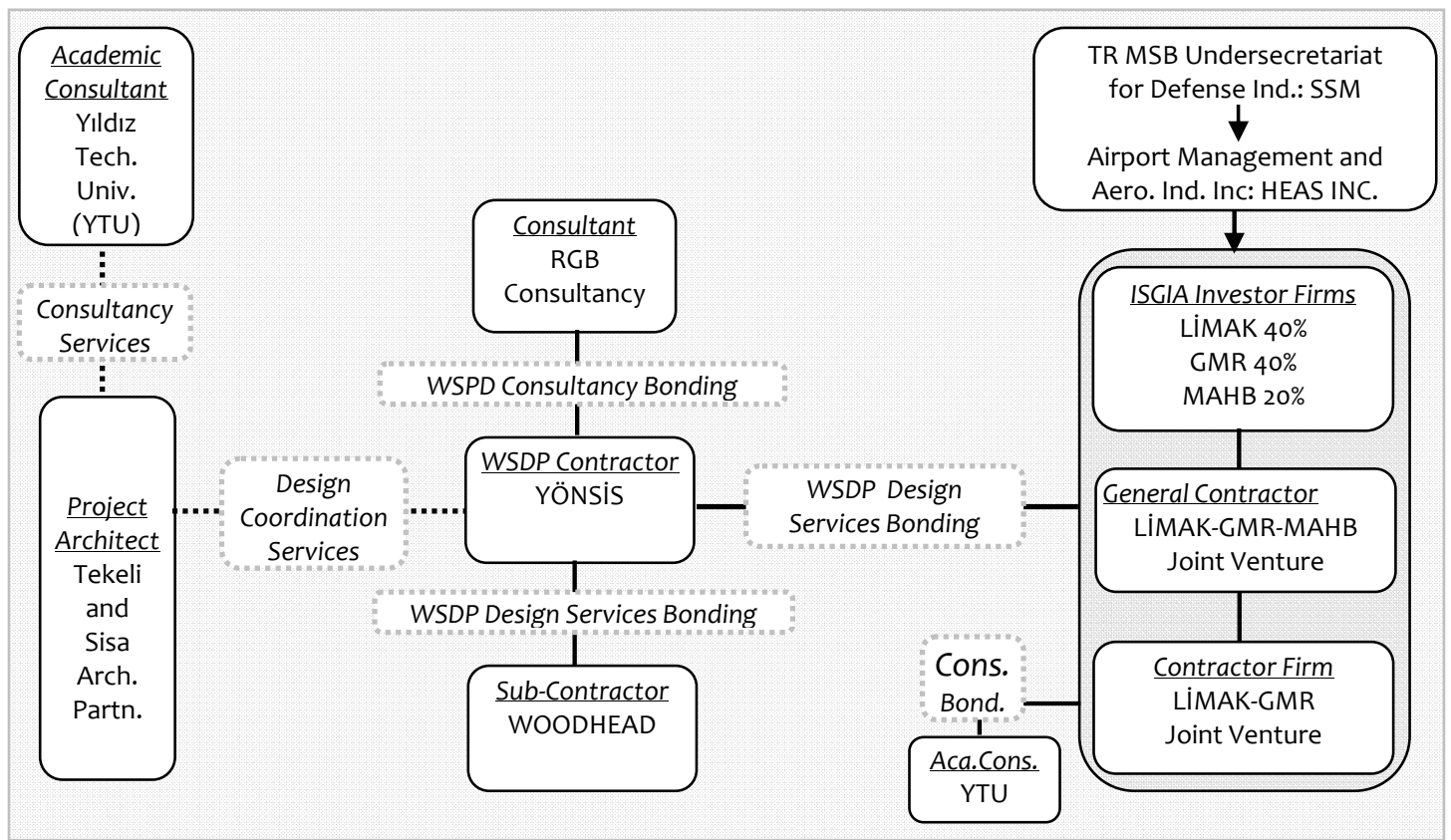

Figure 1. Sabiha Gökçen International Airport Wayfinding and Signage Design Project Organizational Schema [Source: Adopted from Can, (2010)]

Coordination theory of Malone (1988) is operationalized for coordinative measures. A body of principles defined by Malone (1988) about how the activities of separate actors can be coordinated are utilized for this study and further explained below. Differences in coordinative activities of project actors are analyzed via extracted key phrases from relevant sentences of email dataset of WSDP project actors. Coordination score of each actor is measured empirically. Then electronic information exchange of WSDP project actors is used to facilitate mapping of SNA, then network centrality analysis is built on email frequency. Different centrality codings as degree, betweenness and closeness are measured. The methodology of the study involves four research phases: (1) Activating Malone's (1988) coordination theory for email dataset of WSDP; (2) Calculation of coordination scores for WSDP actors; (3) Conducting SNA for email information exchange network of WSDP; (4) Calculation of network centrality measures for WSDP actors.

Malone (1988) defines coordination as managing dependencies between activities. Malone and Crowston (1994) characterize four different kinds of dependencies and identify the coordination processes that can be used to manage them. Although coordination is abstract and difficult to quantify, Hossain et al. (2006) and Hossain (2009) measured coordination depending on the effectiveness of key coordination processes defined by Malone and Crowston (1994). Measurements are taken as (1) the actor's ability to effectively coordinate scarce resources and to maximize their impact, (2) the actor's ability to manage the producer/consumer relationships via transfer of information between other actors of the network, (3) the actor's ability to manage simultaneity constraints setting up task synchronization between actors, (4) the actor's ability to manage tasks/subtasks effectively for achieving higher-level objectives. Activating coordination theory sets off by identifying coordination processes such as for managing resource dependency (Table 1). Then interpretations for WSDP are specifically made for previously identified coordination processes for managing resource dependency. This is followed by key 
phrase identification which is based on the interpretations for WSDP (Table 1). Key phrase identification is specific to the context and done by manual review in this study. Giddens (1984) argue that coordinative action is historically situated, culturally embedded, and generally stands in a recursive relation to action. Pentland (1994) also states that it is difficult to imagine an institutional, technological, cultural, or coordination constraint that does not vary with context. Accordingly, there is no universal grammar for organizational processes and this study used a context of specific categorization for key phrase identification. The four processes along with their interpretations for WSDP, extracted key phrase instances and assigned weights are shown in Table 1.

Table 1. Procedure for Activating Coordination Theory

\begin{tabular}{|c|c|c|c|c|}
\hline Dependency & $\begin{array}{l}\text { Coordination } \\
\text { processes } \\
\text { for managing resource } \\
\text { dependency } \\
\text { (adopted from Malone and } \\
\text { Crowston, 1994) }\end{array}$ & $\begin{array}{l}\text { Interpretation for } \\
\text { WSDP }\end{array}$ & $\begin{array}{l}\text { Examples of } \\
\text { Coordinative } \\
\text { key Phrases }\end{array}$ & Weight \\
\hline $\begin{array}{l}\text { SHARED } \\
\text { RESOURCES }\end{array}$ & $\begin{array}{ll}\text { - } & \text { Priority order } \\
\text { - } & \text { Budgeting processes } \\
\text { - } & \text { Managerial decision } \\
\text { - } & \text { Organizational power } \\
\text { - } & \text { Resource dependence } \\
& \text { etc... }\end{array}$ & $\begin{array}{ll}\text { - } & \text { Ordering tasks, } \\
\text { Directing } \\
\text { processes or } \\
\text { Asking to } \\
\text { complete a task }\end{array}$ & $\begin{array}{l}\text { Please send } \\
\text { Please make sure } \\
\text { Please submit } \\
\text { Please get } \\
\text { Please upload } \\
\text { Please prepare } \\
\text { Please change } \\
\text { Please organize }\end{array}$ & $\begin{array}{l}4.95 \\
2.32 \\
2.00 \\
2.00 \\
1.58 \\
1.00 \\
1.00 \\
1.00\end{array}$ \\
\hline $\begin{array}{l}\text { SIMULTANEITY } \\
\text { CONSTRAINTS }\end{array}$ & $\begin{array}{ll}\text { - } & \text { Scheduling, } \\
\text { - } & \text { Synchronization } \\
\text { - } & \text { Meeting scheduling } \\
\text { - } & \text { Certain kinds of } \\
& \text { process modeling }\end{array}$ & 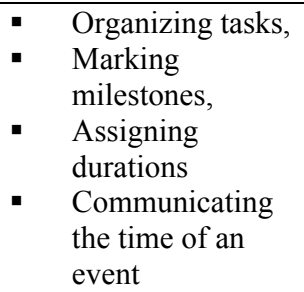 & $\begin{array}{l}\text { Arrange } \\
\text { Due (date) } \\
\text { Meeting call } \\
\text { Make a schedule } \\
\text { Submission date } \\
\text { Given time } \\
\text { Required time } \\
\text { etc... }\end{array}$ & $\begin{array}{l}4.75 \\
4.32 \\
3.00 \\
2.58 \\
0.30 \\
0.30 \\
0.30\end{array}$ \\
\hline $\begin{array}{l}\text { TASKS / } \\
\text { SUBTASKS }\end{array}$ & 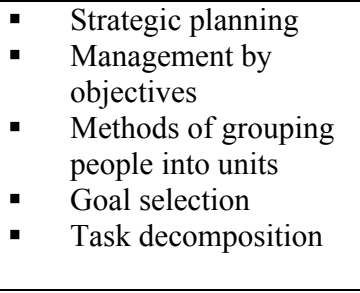 & $\begin{array}{ll}\text { - } & \text { Planning tasks } \\
\text { - } & \begin{array}{l}\text { Decide on a task } \\
\text { objective }\end{array} \\
\text { - } & \text { Intend for a work } \\
\text { package } \\
\text { - } \quad \begin{array}{l}\text { Challenging } \\
\text { higher-level } \\
\text { objectives }\end{array} \\
\end{array}$ & $\begin{array}{l}\text { I recommend } \\
\text { I need to } \\
\text { I think } \\
\text { I can add } \\
\text { In order to finish } \\
\text { For changing } \\
\text { We can redesign } \\
\text { We should revise }\end{array}$ & $\begin{array}{l}3.70 \\
3.58 \\
3.46 \\
3.00 \\
2.80 \\
2.58 \\
2.32 \\
2.23 \\
\end{array}$ \\
\hline $\begin{array}{l}\text { PRODUCER } \\
\text { /CONSUMER } \\
\text { RELATIONSHIPS }\end{array}$ & $\begin{array}{ll}\text { - } & \text { Participatory design } \\
\text { - } & \text { Market research } \\
\text { - } & \text { Inventory } \\
\text { - } & \text { Management } \\
\text { - } & \text { Sust In Time) } \\
\text { - } & \text { Concurrent } \\
\text { engineering }\end{array}$ & $\begin{array}{ll}\text { - } & \text { Ask information } \\
\text { - } & \text { Pass information } \\
\text { - } & \text { Balancing } \\
& \text { simultaneous } \\
\text { - } & \text { Cffort } \\
& \text { Correspondence }\end{array}$ & $\begin{array}{l}\text { I sent } \\
\text { Attached is } \\
\text { I uploaded } \\
\text { ASAP } \\
\text { For your } \\
\text { information } \\
\text { I provide } \\
\text { I updated } \\
\text { Please download } \\
\text { The file is } \\
\text { available }\end{array}$ & $\begin{array}{l}6.55 \\
5.95 \\
4.95 \\
3.46 \\
3.00 \\
\\
2.80 \\
2.00 \\
1.58 \\
1.00\end{array}$ \\
\hline
\end{tabular}

Weight assignment procedure is explained in the next section, namely calculating coordination scores. Coordinative activity of each actor is evaluated by the actor's 
coordination score. The first step to the calculation of coordination scores was the extraction of sentences indicative of one of the four coordination processes (Malone and Crowston, 1994). Each sentence was classified under the specific coordination process. Then the list of sentences was sorted out and the key phrases which underlined the coordinative action were marked. Second step is the cataloguing of coordination key phrases. Marked key phrases extracted from the sentences and then catalogued for each coordination process. In the third step, each coordination phrase was assigned a weight regarding to its frequency of use. The method used for assigning coordination weights was formulated referring to Hossain's (2009) study. Accordingly, the number of usage of a specific key phrase in coordinative sentences of all actors is counted in order to determine frequency. The base two log of the determined frequency is assigned to be the weight of that phrase. Base two logs are used to prevent fluctuations and create a normal distribution. Weights of all key phrases ranged between 0.30 and 6.55. This process of WSDP email dataset refinement leading to weighted key phrases is shown in Figure 2.

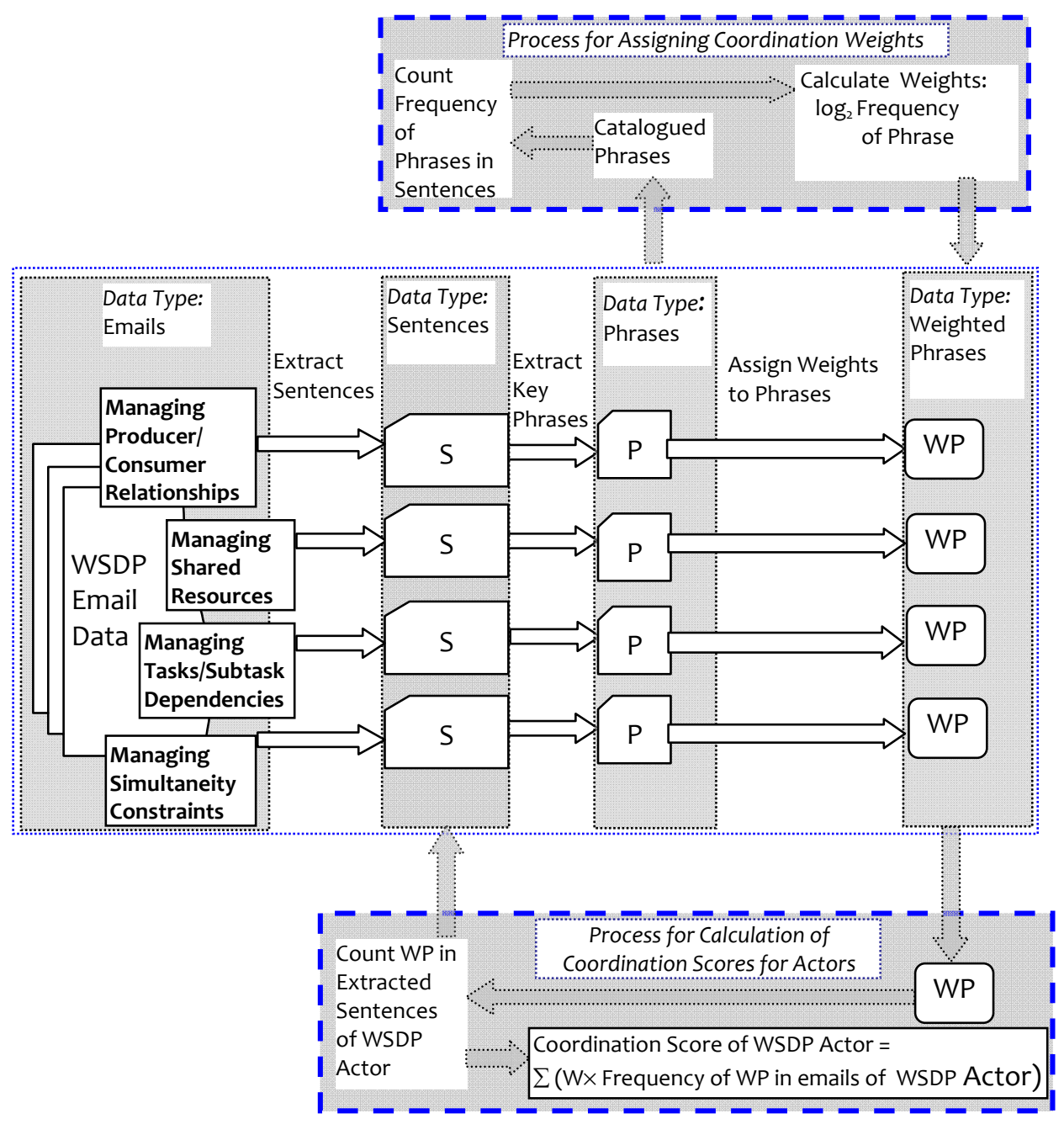

Figure 2. Procedure for Calculation of Coordination Scores

Figure 2 also depicts the processes for assigning coordination weights and calculation of coordination scores for actors. The weighted coordination score of each actor was 
calculated by the sum-product of the phrase frequency and its assigned weight. Table 2 shows the coordination scores for WSDP actors.

Table 2. Coordination Scores of WSDP Actors

\begin{tabular}{clc}
\hline Rank & Actor & Coordination Score \\
\hline 1 & WSDP Consultant (RGB Consulting) & 1329.48 \\
2 & WSDP Contractor (Yönsis) & 1068.94 \\
3 & Sub-Contractor (Woodhead) & 362.80 \\
4 & General Contractor (Limak and GMR JV) & 327.82 \\
5 & Academic Consultant (Yıldı Tech. Uni.) & 90.66 \\
6 & Project Author (Tekeli-Sisa Arch. Part.) & 35.77 \\
\hline
\end{tabular}

The last step of the methodology is the calculation of network centrality measures for WSDP actors. Centrality measurements depend on social network analysis (SNA). SNA is a methodology used to identify the relational conditions of social structures by examining the interactions and the interrelationships among a set of actors (Park et al., 2011). SNA emphasizes the structure of social relationships and investigates their causes and consequences by relational measures. A relational structure can be recognized in communication flows such as electronic mailing. SNA software UCINET developed by Borgatti et al. (2002) is used to depict a graph of information exchange network for e-mail data in this study (Figure 3).

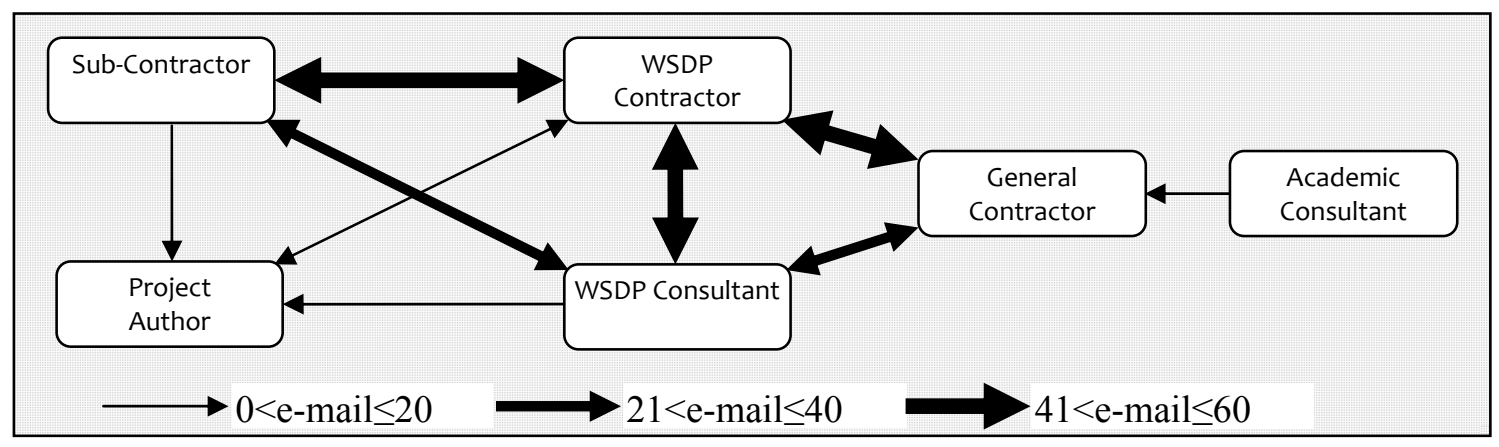

Figure 3. Weighted Directional Graph of Information Exchange Network

The graph applied directional analysis indicating sending and receiving of emails as distinct activities. The sent and received e-mails by each actor of the WSDP were added up provided that the recipient is the direct one other than the recipients of carbon copy ("CC" or "BCC" types). The frequency of the scored e-mails is reflected in weighted arrows (Figure 3). In the network graph, connection ties represent information exchange and nodes represent actors (Figure 3). Centrality is a direct indicator which describes the power and the influence of an actor by measuring how strategically he/she is connected in the network. Freeman (1979) defined three main types of centrality as degree, betweenness and closeness centrality. Degree denotes the number of nodes connected to one node in particular. Betweenness signifies the extent to which a node lies between other pairs of nodes. It is the proportion of all the shortest paths (i.e., geodesic) between pairs of other nodes that pass through the node. Closeness is based on the sum of the geodesic distances from each node to all others (Hanneman and Riddle, 2005). For the directed information network, degree and 
closeness are classified as in- and out- depending on the direction of the relationship. The following equations (1), (2) and (3) show the mathematical forms of degree, betweenness, and closeness centrality (de Nooy et al., 2005):

Degree Centrality $=\sum_{j=1}^{n}\left(Z_{i j}+Z_{j i}\right) / \sum_{i=1}^{n} \sum_{j=1}^{n}\left(Z_{i j}\right)$, where $Z_{i j}=$ number of degree that a node $i$ receives from a node $j$ and $n=$ number of existent nodes.

Betweenness Centrality (of node $i$ ) $=\sum_{s, t: s \neq t \neq i} \frac{\sigma_{i}(s, t)}{\sigma(s, t)}$, where $\sigma_{i}(s, t)=$ the number of shortest paths from node $s$ to node $t$ that pass through node $i$.

Closeness centrality (of node $i$ ) $=\frac{n-1}{\sum_{k \in N} d(i, k)}$, where $n=$ number of nodes; $N=$ total nodes; $k=k^{\text {th }}$ node in the network; and $d(i, k)=$ the length of the shortest path between node $i$ and $k$.

For this study, UCINET (2002) provided mathematical measurements of centrality calculations (Table 3). Normalization factor is used to make the definition independent of the size of the network and to have centrality values between 0 and 1 .

Table 3. Degree, Betweenness and Closeness Centrality Measures

\begin{tabular}{lccccc}
\hline Actor & $\begin{array}{l}\text { Out- } \\
\text { Degree }\end{array}$ & $\begin{array}{l}\text { In- } \\
\text { Degree }\end{array}$ & $\begin{array}{l}\text { Between } \\
\text {-ness }\end{array}$ & $\begin{array}{l}\text { In- } \\
\text { Close } \\
\text {-ness }\end{array}$ & $\begin{array}{l}\text { Out- } \\
\text { Close } \\
\text {-ness }\end{array}$ \\
\hline WSDP Contractor (Yönsis) & 0.80 & 0.80 & 0.28 & 0.16 & 0.10 \\
WSDP Consultant (RGB Consulting ) & 0.80 & 0.60 & 0.13 & 0.14 & 0.10 \\
Sub-Contractor (Woodhead) & 0.60 & 0.40 & 0.00 & 0.11 & 0.09 \\
General Contractor (Limak \& GMR JV) & 0.40 & 0.60 & 0.20 & 0.14 & 0.08 \\
Project Author (Tekeli-Sisa Arch. Partn.) & 0.20 & 0.60 & 0.00 & 0.13 & 0.07 \\
Academic Consultant (Yildiz Tech. Uni.) & 0.20 & 0.00 & 0.00 & 0.03 & 0.09 \\
\hline
\end{tabular}

\section{FINDINGS AND DISCUSSIONS}

Centrality measurements and coordination scores calculated for this study are compared. The results support previous findings that network centrality position has an effect on coordination (Freeman et al., 1979/80). WSDP Contractor (Yönsis) was favorably positioned in the WSDP organization schema (Figure 1) and SNA weighted directional graph of information exchange network (Figure 3). Also, it was found that it has the most central position in terms of degree, betweenness and closeness centrality (Table 3 ). In this study, out-degree and out-closeness centralities were found to be the closest predictors for coordination. Actors who display high outdegree centrality are said to be the influential actors (Hanneman and Riddle, 2005). Latora and Marchiori (2007) pointed that an actor with a higher out-degree provides direct information to other actors and by being very visible he/she is immediately recognized by others as a hub, a very active point and major channel of communication. The out-closeness measures reflect the freedom of control by other actors (Freeman, 1979). Findings suggest that outward connections define coordinators for this study. Two leading coordinators of the network are recognized to supply information to other actors in an uncontrolled free direction. High 
betweenness index assigns coordinator task because the position dictates a role of leadership, such as the actor would lie between many other actors and thus have greater influence for diffusion of information (Granovetter, 1973; Chinowsky et al., 2010). Although such previous research statements are still valid for this study, it is also observed that the higher betweenness and in-closeness centrality measures weakened coordinative action. The controlled acceptance of information delayed independent coordination.

\section{CONCLUSIONS}

This study utilized coordination theory and social network approach to learn about the roles of actors of ISGIA WSDP in the information exchange network and their coordination performance in one of the Turkish multinational construction projects. While activating existing coordination process theory, coordination scores from a dataset of emails were calculated. Using SNA method, weighted directional graph of information exchange network was demonstrated. Then a relationship between coordination and network centrality is explored. The methodology was based on Hossain's study (2009) and tested extensibility of previous findings to assist relevant research. The further integration of the artificial intelligence methods to the adopted methodology for investigation of centrality and coordination association is an ongoing study of the authors. The findings of this study are in line with the findings of Freeman, et al. (1979/80); Hossain et al. (2006) and Hossain (2009) that network centrality position has an effect on coordination. These findings also support the power of social networks in affecting design and construction project actors' coordinative interactions. This study extended the work of Hossain et al. (2006) and Hossain (2009) with empirical evidence to show that out-centrality measures define coordination process better than in-centrality measures. Consequently, the study supports that centrally positioned actors in design and construction projects demonstrate greater coordination performance than other project actors within the network. The findings imply that for streamlining knowledge sharing and coordination processes in construction project environments social network structures are vital means. In particular, project actors who are most active in providing information in a direct manner released from the influence of others are candidates of leading coordinators as their network positioning establishes the role of a communication hub that balances organizational network and information network.

\section{REFERENCES}

Borgatti, S.P., Everett, M.G., and Freeman, L.C. (2002). UCINET for Windows: Software for Social Network Analysis, Analytic Technologies, Harvard, MA.

Can, N. (2010). Design Management in Construction Projects and a Case Study in One Design-Build Construction project, Master Thesis, Istanbul Technical University, Istanbul, Turkey.

Chan, A.P.C., Chan, D.W.M., Chiang, Y.H., Tang, B.S., Chan, E.H.W. and Ho, K.S.K. (2004) Exploring Critical Success Factors for Partnering in Construction Projects, $J$. of Const. Eng. and Man., 130(2), 188-198.

Cheng, M.Y., Su, C.W., and You, H.Y., (2003). Optimal Project Organizational Structure for Construction Management, J. of Const. Eng. and Man., (January/February), 71.

Chinowsky, P., Diekmann, J., Galotti, V. (2008). Social Network Model of Construction, J. of Const. Eng. and Man., 134(10), 804-812. 
Chinowsky, P., Diekmann, J., and O'Brien, J. (2010). Project Organizations as Social Networks, J. of Const. Eng. and Man., ASCE, 136(4), 452-458.

Chitkara, K.K. (1998). Construction Project Management: Planning, Scheduling and Controlling, McGraw-Hill, New Delhi.

De Nooy, W., Mrvar, A., and Batageli, V. (2005). Exploratory social network analysis with Pajek, Cambridge University Press, Cambridge, UK.

Erbasaranoglu, B. (2011). Analyzing the Communication and Coordination Processes in Sabiha Gokcen International Airport's New Terminal Building Wayfinding Project, Master Thesis, Izmir Institute of Technology, Izmir, Turkey.

Freeman, L.C. (1979). Centrality in Social Networks: Conceptual Clarification, Social Networks, 1(3), 215-239.

Freeman, L.C., Roeder, D. and Mulholland, R.R. (1979/80). Centrality in Social Networks: ii. Experimental Results. Social Networks, 2(2), 119-141.

Giddens, A. (1984). The Constitution of Society: Outline of the Theory of Structuration, University of California Press, Berkeley.

Granovetter, M.S. (1973). The Strength of Weak Ties, The American J. of Soc., 78(6), 13601380.

Hanneman, R.A., and Riddle, M. (2005). Introduction to Social Network Methods, University of California, Riverside, CA.

Hossain, L., Wu, A., Chung, K.K.S. (2006). Actor Centrality Correlates to Project Based Coordination, CSCW'06, Banff, Alberta, Canada.

Hossain, L. (2009). Communications and Coordination in Construction Projects, Const. Man. and Econ., 27(1), 25-39.

Latora, V. and Marchiori, M. (2007). A Measure of Centrality Based on the Network Efficiency, New J. of Phy., 9, 188.

Loosemore, M. (1998). Social Network Analysis: Using a Quantitative Tool within an Interpretative Context to Explore the Management of Construction Crises, Eng. Const. and Arch. Man., 5(4), 315-326.

Malone, T.W. (1988). What is Coordination Theory? National Science Foundation Coordination Theory Workshop, SSM WP 2051-2088, Massachusetts Institute of Technology, Cambridge, MA.

Malone, T.W. and Crowston, K. (1994). The Interdisciplinary Study of Coordination, ACM Computing Surveys, 26(1), 87-119.

Mokhtar, A., Bedard, C., and Fazio, P. (1998) Information Model for Managing Design Changes in a Collaborative Environment, J. of Comp. in Civil Eng., 12(2), 82-92.

Park, H., Han, S.H., Rojas, E.M., Son, J.W. and Jung, W. (2011). Social Network Analysis of Collaborative Ventures for Overseas Construction Projects, J. of Const. Eng. and Man., 137(5), 344- 355.

Pentland, B.T. (1994). Grammatical Models of Organizational Processes, CCS Working Paper No. 176, Sloan WP 3720-3794.

Pryke, S.D. (2004). Analysing Construction Project Coalitions: Exploring the Application of Social Network Analysis, Const. Man. and Econ., 22(8), 787-797.

Pryke, S.D. (2005). Towards a Social Network Theory of Project Governance, Const. Man. and Econ., 23(9), 927-939.

Pryke, S.D. (2006). Legal Issues Associated with Emergent Actor Roles in Innovative UK procurement: Prime Contracting Case Study, J. of Pro. Iss. in Eng. Ed. and Prac., 132(1), 67-76.

Saram, D.D. and Ahmed, S.M. (2001). Construction Coordination Activities: What is Important and What Consumes Time, J. of Man. in Eng., 17(4), 202-212.

Taylor, J.E. and Bernstein, P.G. (2009). Paradigm Trajectories of Building Information Modeling Practice in Project Networks, J. of Man. in Eng., 25(2), 69-76. 